NASA Technical Memorandum 105692

$$
\begin{aligned}
& \text { NASA-TM-105692 } \\
& \text { Conf } 920801--33
\end{aligned}
$$

\title{
Heat Transfer in Oscillating Flows With Sudden Change in Cross Section
}

Mounir Ibrahim and Waqar Hashim

Cleveland State University

Cleveland, Ohio

and

Roy C. Tew and James E. Dudenhoefer

Lewis Research Center

Cleveland, Ohio

Prepared for the

27th Intersociety Energy Conversion Engineering Conference

cosponsored by the SAE, ACS, AIAA, ASME, IEEE, AIChE, and ANS

San Diego, California, August 3-7, 1992 


\section{DISCLAIMER}

This report was prepared as an account of work sponsored by an agency of the United States Government. Neither the United States Government nor any agency Thereof, nor any of their employees, makes any warranty, express or implied, or assumes any legal liability or responsibility for the accuracy, completeness, or usefulness of any information, apparatus, product, or process disclosed, or represents that its use would not infringe privately owned rights. Reference herein to any specific commercial product, process, or service by trade name, trademark, manufacturer, or otherwise does not necessarily constitute or imply its endorsement, recommendation, or favoring by the United States Government or any agency thereof. The views and opinions of authors expressed herein do not necessarily state or reflect those of the United States Government or any agency thereof. 


\section{DISCLAIMER}

Portions of this document may be illegible in electronic image products. Images are produced from the best available original document. 


\title{
HEAT TRANSFER IN OSCILLATING FLOWS WITH SUDDEN CHANGE IN CROSS SECTION
}

\author{
Mounir Ibrahim and Waqar Hashim \\ Cleveland State University \\ Cleveland, Ohio 44115
}

and

Roy C. Tew and James E. Dudenhoefer

National Aeronautics and Space Administration

Lewis Research Center

Cleveland, Ohio 44135

\section{ABSTRACT}

Oscillating fluid flow (zero mean) with heat transfer, between two parallel plates with a sudden change in cross section, was examined computationally. The flow was assumed to be laminar and incompressible with inflow velocity uniform over the channel cross section but varying sinusoidally with time. Over 30 different cases were examined; these cases cover wide ranges of $\mathrm{Re}_{\max }$ (187.5 to $30000), \mathrm{Va}(1$ to 350$)$, expansion ratio $(1: 2,1: 4,1: 8$, and $1: 12)$ and $A_{r}(0.68$ to 4$)$. Three different geometric cases were considered (asymmetric expansion/contraction, symmetric expansion/contraction, and symmetric blunt body). The heat transfer cases were based on constant wall temperature at higher (heating) or lower (cooling) value than the inflow fluid temperature. As a result of the oscillating flow, the fluid undergoes sudden expansion in one-half of the cycle and sudden contraction in the other half. In this paper, one heating case is examined in detail, and conclusions are drawn from all the cases (documented in detail elsewhere). Instantaneous friction factors and heat transfer coefficients, for some ranges of $\mathrm{Re}_{\max }$ and $\mathrm{Va}$, deviated substantially from those predicted with steady-state correlations.

\section{NOMENCLATURE}

\begin{tabular}{|c|c|}
\hline$A_{r}$ & relative fluid displacement $\left(2 X_{\max } / L\right)$ \\
\hline $\begin{array}{l}D_{h} \\
f\end{array}$ & $\begin{array}{l}\text { hydraulic diameter of the smaller size channel } \\
\text { instantaneous friction factor }\left(2 \tau_{w} / \rho \mathrm{U}^{2}\right)\end{array}$ \\
\hline $\mathbf{L}$ & length of channel \\
\hline $\operatorname{Re}$ & instantaneous Reynolds number \\
\hline $\mathbf{R e}_{\max }$ & maximum Reynolds number $\left(U_{\max } D_{h} / v\right)$ \\
\hline $\mathbf{S}$ & step size (see Fig. 1) \\
\hline St & Strouhal number $\left(4 \mathrm{Va} / \mathrm{Re}_{\max }\right)$ \\
\hline $\mathrm{U}$ & $X$-component of velocity \\
\hline V & Y-component of velocity \\
\hline Va & Valensi number $\left(\omega D_{h}^{2} / 4 v\right)$ \\
\hline$X$ & distance along channel axis \\
\hline $\mathrm{X}_{\max }$ & amplitude of fluid displacement \\
\hline $\mathrm{Y}$ & distance normal to channel axis \\
\hline$\rho$ & density of fluid \\
\hline$\mu$ & dynamic viscosity of fluid \\
\hline$\omega$ & frequency of oscillation \\
\hline \multicolumn{2}{|c|}{ Subscripts: } \\
\hline in & inlet condition \\
\hline ss & steady state \\
\hline$w$ & at the wall \\
\hline
\end{tabular}

\section{INTRODUCTION}

Several engineering applications involve unsteady flow as well as sudden changes in cross-sectional area. In free-piston Stirling engines, the flow oscillates around a zero mean while sudden changes in cross section take place at component interfaces. For example, in the Space Power Research Engine (SPRE), the flow goes through sudden changes in cross section at the expansion space/heater, heater/ regenerator, regenerator/cooler, and cooler/compression space interfaces. Currently, steady-state correlations for fluid friction and heat transfer (which also account for steady-state $L / D_{h}$ or end effects) are used in the design of Stirling engines.

For oscillating, zero-mean flow through a sudden change in cross-sectional area, the fluid undergoes sudden expansion in one-half of the cycle and sudden contraction in the other half. In addition to the imposed (sinusoidal) flow reversal, the sudden expansion portion of the cycle results in a time varying recirculation zone downstream of the step.

Experiments have been conducted to investigate the hydrodynamics of oscillating flow in a circular pipe $[1,2]$. These measurements show velocity profiles differing significantly from steady flow; they also indicate a friction factor significantly larger than predicted by steady-flow correlations, during the laminar flow part of the cycle.

Several numerical investigations have been conducted to examine laminar oscillating flows with heat transfer in uniform circular pipes and parallel plate channels $[3,4]$. Velocity and temperature profiles were found to differ significantly from the steady-flow case. Also, friction factor and heat transfer coefficients were considerably different than indicated by steady-flow correlations.

A literature survey showed that several investigations have been conducted for flows with a sudden change in cross-sectional area. Examples involve steady unidirectional flow over a backward facing step [5-8] and flow through a sudden contraction in a channel [9-11]. These results showed higher friction factor as compared to a uniform geometry under similar flow conditions.

In this paper, results from a computational study of oscillating fluid flow with heat transfer, between two parallel plates with a sudden change in cross section, are presented. The flow parameters were selected to emulate the SPRE. A more complete documentation of the computational results of the study, including cases for different geometries and expansion ratios, is given by Hashim [12]. 


\section{ANALYSIS}

ASSUMPTIONS - Figure 1(a) shows a parallel plate channel with a sudden change in cross section; it also shows the Cartesian coordinate system used for this analysis. The analysis concentrated on the asymmetric expansion/contraction of Fig. 1(a), after it was determined that the symmetric expansion/contraction of Fig. 1(b) and the symmetric blunt body of Fig. 1(c) did not yield any unique computational results of interest for this study. The following assumptions were made: (1) the flow is laminar incompressible with constant thermophysical properties; (2) the inlet velocity is uniform, spatially, but varies sinusoidally with time; (3) the location of the step is far away from either end. Under these assumptions the NavierStokes equations were simplified [12].

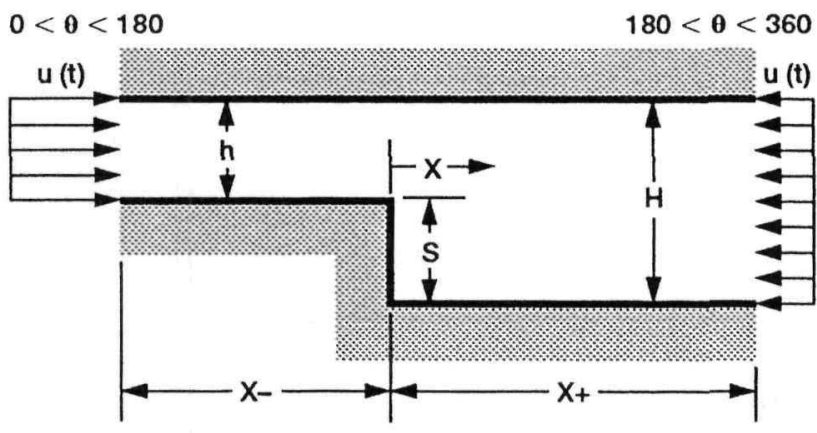

(a) Asymmetric expansion/contraction.

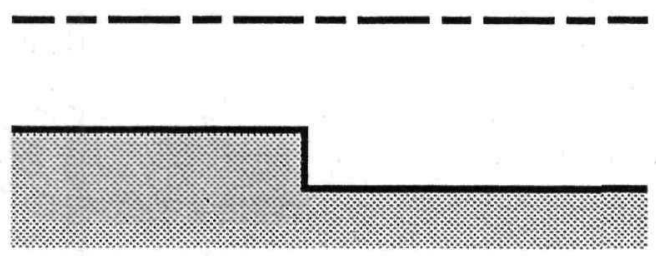

(b) Symmetric expansion/contraction.

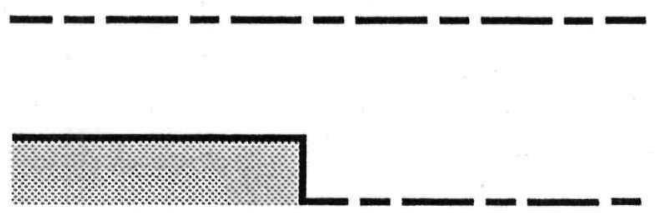

(c) Symmetric blunt body.

Figure 1.-Different geometries examined.

BOUNDARY CONDITIONS - The momentum and energy equations are parabolic in time and elliptic in space coordinates. Therefore, the boundary conditions are required along all spatial boundaries of the solution domain: (1) solid walls: no slip and no jump conditions, (2) axis of symmetry: zero velocity and enthalpy gradients normal to the axis, (3) inlet plane: uniform velocity and temperature profiles, but the velocity varies sinusoidally with time, and (4) outlet plane: zero velocity and enthalpy gradients in the axis direction; this is consistent with the assumption of fully-developed flow and thermal fields at the outlet. It should be noted that for oscillating flows the inlet and outlet planes are switched at the appropriate time step so that a flow reversal is implemented numerically.

NUMERICAL METHOD - The analysis utilizes a modified version of the computer code, CAST, developed by Peric and
Scheuerer [13]. CAST solves two-dimensional (2-D) Navier-Stokes equations for laminar or turbulent flows utilizing a collocated grid. It has been modified to handle time dependent boundary conditions for oscillating flows. A special velocity-pressure coupling [13] is used, based on the staggered grid concept to prevent an oscillatory pressure solution [14]. The solution procedure employed is Patankar's well known SIMPLE algorithm [14].

For all cases investigated, the flow cycle was divided into 60 time steps of $6^{\circ}$ intervals. At least three cycles were run for each case to achieve a converged solution ( 0.2 percent convergence criteria). CPU time required on Cray X-MP/Y-MP's ranged from 3600 to $8000 \mathrm{sec}$ (for three cycles), depending upon the mesh size.

CODE VALIDATIONS - Several computational experiments were conducted to validate the CAST code: (1) Steady-flow predictions for reattachment length and the minimum and maximum velocities at various locations along the channel axis, for $\operatorname{Re}=50$ and 150 and expansion ratios of $1: 1.2$ and 1:1.5, were compared with similar results by Morgan et al. [8]; the comparisons showed good agreement. (2) Comparisons were made with numerical computations of Chiu [6] for steady flow over a backward facing step, asymmetric channel with 1:1.5 expansion ratio and $\mathrm{Re}=916$. Predictions for friction factor were within 5 percent of Chiu's results. (3) Predicted size of the recirculation zone before the step, for a forward facing step with $\mathrm{Re}=200$, was compared with the numerical computations of Mei, and Plotkin [11]. The agreement was within 2 percent. (4) Also, computations were made for impulsively started flow over a backward facing step with $\mathrm{Re}=400$ and $1: 2$ expansion ratio. The solution was marched in time. Friction factor and reattachment length were compared with steady flow results for the same case. The agreement was within 1 percent. Similar agreement was found upon examining the case of a forward facing step. (5) Finally, unsteadyflow calculations were made for oscillating flow in a straight channel. The results were in excellent agreement with Kurzweg's analytical solutions for fully developed channel flow [4].

\section{RESULTS AND DISCUSSION}

Tables I and II list some of the cases computed by Hashim [12] for the geometry of Fig. 1(a). These cases cover wide ranges of

Table I.-Summary of test cases corresponding to Stirling engine

\begin{tabular}{|c|c|c|c|c|c|c|}
\hline $\begin{array}{c}\text { Test } \\
\text { case }\end{array}$ & $\begin{array}{c}\text { Expan- } \\
\text { sion } \\
\text { ratio }\end{array}$ & Re $_{\text {mux }}$ & Va & Ar & Tw/Tin & MESH \\
\hline H1 & $1: 2$ & 16500 & 88.0 & 2.0 & 1.05 & $84 \times 22$ \\
H2 & $1: 2$ & 16500 & 88.0 & 1.32 & 1.05 & $94 \times 22$ \\
H3 & $1: 2$ & 8250 & 44.0 & 1.56 & 1.05 & $92 \times 22$ \\
H4 & $1: 4$ & 16500 & 88.0 & 1.32 & 1.05 & $92 \times 32$ \\
H5 & $1: 8$ & 16500 & 88.0 & 1.32 & 1.05 & $92 \times 42$ \\
H6 & $1: 12$ & 16500 & 88.0 & 1.32 & 1.05 & $92 \times 42$ \\
\hline
\end{tabular}

Table II.-Summary of test cases corresponding to Stirling engine cooler.

\begin{tabular}{|c|c|c|c|c|c|c|}
\hline $\begin{array}{c}\text { Test } \\
\text { case }\end{array}$ & $\begin{array}{c}\text { Expan- } \\
\text { sion } \\
\text { ratio }\end{array}$ & $\mathrm{Re}_{\max }$ & $\mathrm{Va}$ & $\mathrm{Ar}$ & $\mathrm{Tw} / \mathrm{Tin}$ & $\mathrm{MESH}$ \\
\hline $\mathrm{C} 1$ & $1: 2$ & 30000 & 350.0 & 2.0 & 0.955 & $84 \times 22$ \\
$\mathrm{C} 2$ & $1: 2$ & 30000 & 350.0 & .6857 & .955 & $94 \times 22$ \\
$\mathrm{C} 3$ & $1: 2$ & 15000 & 175.0 & .7142 & .955 & $92 \times 22$ \\
$\mathrm{C} 4$ & $1: 4$ & 30000 & 350.0 & .6857 & .955 & $92 \times 32$ \\
$\mathrm{C} 5$ & $1: 8$ & 30000 & 350.0 & .6857 & .955 & $92 \times 42$ \\
$\mathrm{C} 6$ & $1: 12$ & 30000 & 350.0 & .6857 & .955 & $92 \times 42$ \\
\hline
\end{tabular}


$\mathrm{Re}_{\max }$ (187.5 to 30000 ), $\mathrm{Va}$ (1 to 350 ), expansion ratio (1:2, 1:4, 1:8, and $1: 12$ ), and $\mathrm{A}_{\mathrm{r}}(0.68$ to 4$)$. For heating, inflow temperature was $300 \mathrm{~K}$ and wall temperature was $315 \mathrm{~K}$; for cooling, inflow temperature was $315 \mathrm{~K}$ and wall temperature was $300 \mathrm{~K}$. All Table I cases had the same Strouhal number, St, as the design SPRE heater (0.02133). The Table II cases correspond to the design SPRE cooler
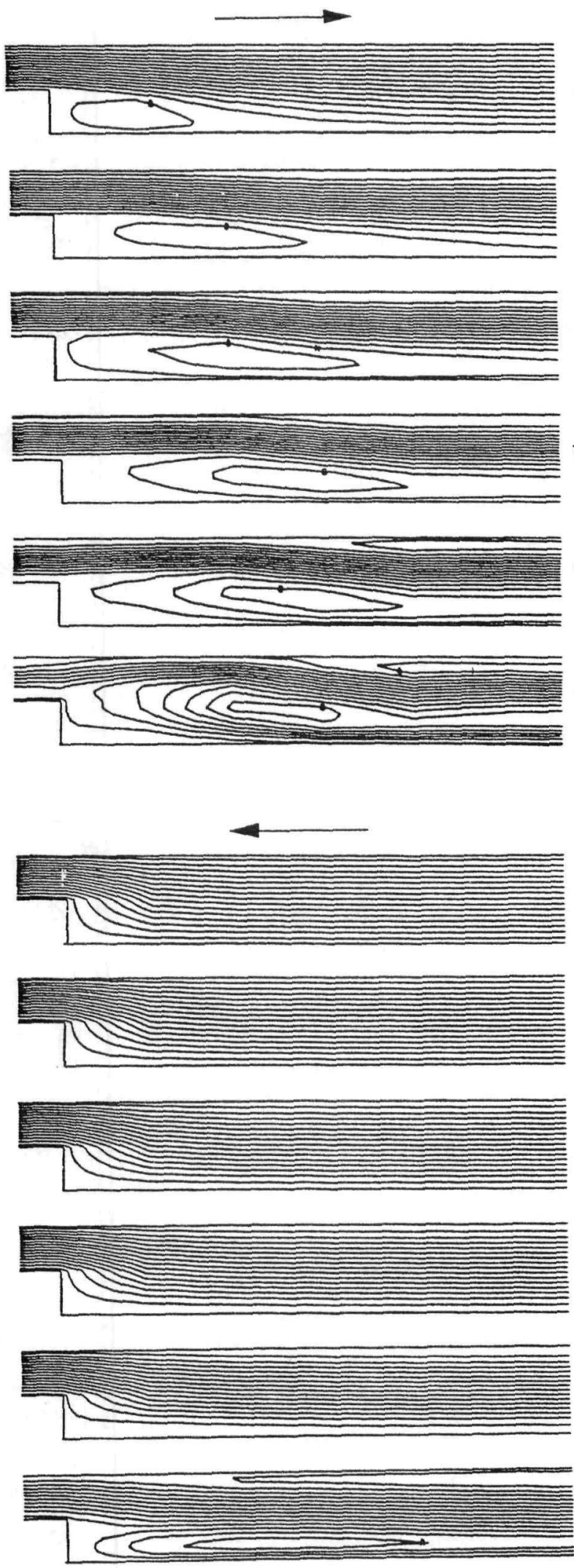

Figure 2.-Streamlines for oscillating flow with asymmetric 1:2 change in cross-section. Re $\max =16500.0, \mathrm{Va}=88.00$.
$(\mathrm{St}=0.04667)$. The inlet velocity, at either end of the channel, varies sinusoidally with time. One of the cases calculated, test case $\mathrm{H} 2$ from Table I, will be discussed in detail and conclusions will be drawn for all cases (see [12] for other case results).

Figure 2 shows the oscillating flow streamlines at different velocity phase angles for case $\mathrm{H} 2\left(\mathrm{Re}_{\max }=16500, \mathrm{Va}=88\right.$, expansion ratio of 1:2). During the fluid acceleration with sudden expansion $\left(0^{\circ}\right.$ to $\left.90^{\circ}\right)$, the size of the recirculation zone increases in magnitude. During the flow deceleration $\left(90^{\circ}\right.$ to $\left.180^{\circ}\right)$, the recirculation zone continues to grow slightly and then remains approximately the same size. This behavior demonstrates the unsteady nature of the flow. It contrasts with quasi-steady oscillating flow (which takes place at lower $\mathrm{Re}_{\max }$ and $\mathrm{Va}$ and is not shown in this paper) where the size of the recirculation zone increases during flow acceleration but then decreases during flow deceleration; the unsteadiness increases with $\mathrm{Re}_{\max }$ or Va. During flow reversal (Fig. 2, $180^{\circ}$ to $360^{\circ}$ ), the recirculation zone disappears completely (sudden contraction).

Figure 3 shows temperature contours at different velocity phase angles for the above case $(\mathrm{H} 2)$. During fluid acceleration with sudden expansion $\left(0^{\circ}\right.$ to $\left.90^{\circ}\right)$, the thermal front advances from the inlet at the left; at the same time the thermal front remaining from the previous half cycle (near outlet, at right), retreats to the right. The front appears relatively stationary during flow deceleration $\left(90^{\circ}\right.$ to $\left.180^{\circ}\right)$. During flow reversal $\left(180^{\circ}\right.$ to $\left.360^{\circ}\right)$, a similar phenomenon occurs in the reverse direction.

For another case, C2 of Table II (plots not shown here), the oscillating-flow streamiines show similar trends to those in Fig. 2. However, the size of the recirculation zone is smaller than for case $\mathrm{H} 2$ at the same cycle time. This is attributed to Case C2's higher Va. Also, for case C2, temperature contour trends are similar to those discussed in Fig. 3, except that the movement of the thermal front is less than for case $\mathrm{H} 2$. This can be explained by the difference in St for the two cases, as follows: From the definition of St (nomenclature), and Tables I and II, it is found that St for case C2 is twice that of case $\mathrm{H} 2$. Since St is the inverse of "the number of hydraulic diameters the fluid travels during the amplitude of its oscillation," the relative (to $D_{h}$ ) amplitude of oscillation for case $C 2$ is half that of case $\mathrm{H} 2$.

FRICTION FACTOR - Figure 4 shows the instantaneous friction factor (as calculated from the previously discussed 2-D computations) normalized by "the corresponding quasi-steady-flow friction factor" (i.e., calculated using the correlation for steady fully developed laminar flat-plate flow, but here based on the instantaneous value of the cross-sectional average Re); it is plotted as a function of dimensionless axial distance at different velocity phase angles, for case H2. Therefore, all plots would collapse on the horizontal line defined by $f / f_{s s}=1$, if the $2-D$ computations had agreed precisely with the quasi-steady-flow friction factor for all spatial locations and times during the cycle. It is seen that the instantaneous friction factor can be an order of magnitude larger than the corresponding quasisteady value. The differences between the instantaneous friction factor and the corresponding quasi-steady one are larger to the right of the step (which occurs at $\mathrm{x} / \mathrm{S}=0$ ); the differences also increased with either $\mathrm{Re}_{\max }$ or Va.

HEAT TRANSFER COEFFICIENT - Figure 5 shows the instantaneous Nusselt number (averaged over both walls) versus dimensionless axial distance at different velocity phase angles, for case H2. It can be seen that the instantaneous Nusselt number can be an order of magnitude larger than the corresponding quasi-steady value (which is a constant $=7.541$ ). Again, as noticed in the frictionfactor results, the difference between the instantaneous Nusselt number and the corresponding quasi-steady one is larger to the right of the step; the differences also increased with either $\mathrm{Re}_{\max }$ or Va. Also, it can be seen that "area-change" effects are noticeable at the 

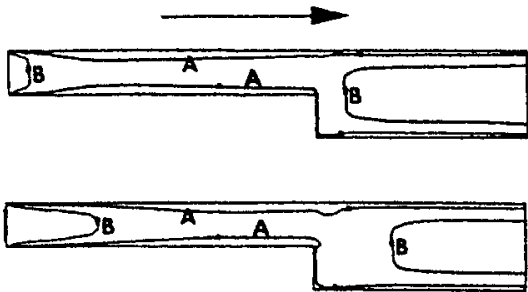

60

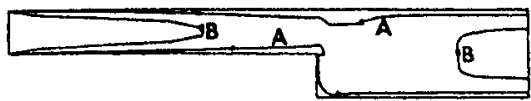

90

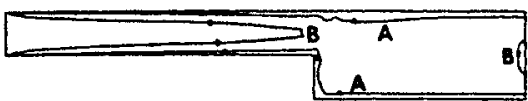

120

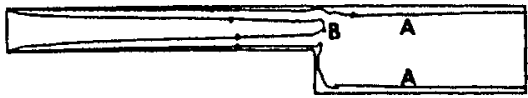

150

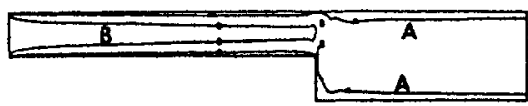

30

180

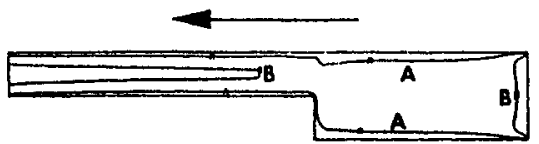

210

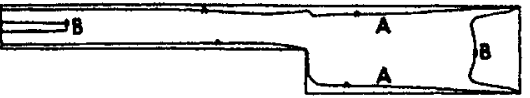

240

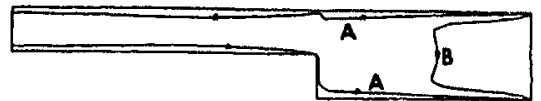

270

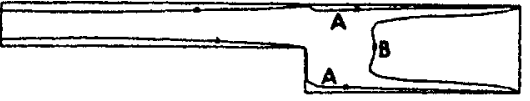

300

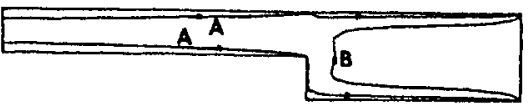

330

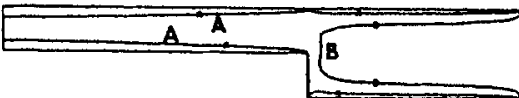

Figure 3.-Temperature contours for oscillating flow with asymmetric $1: 2$ change in cross- section. Re $\max =16500.0, \mathrm{Va}=88.00, A=312 \mathrm{k}, \mathrm{B}=303 \mathrm{k}$.

\section{Degree}

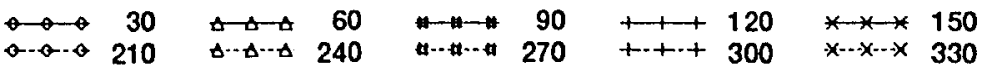

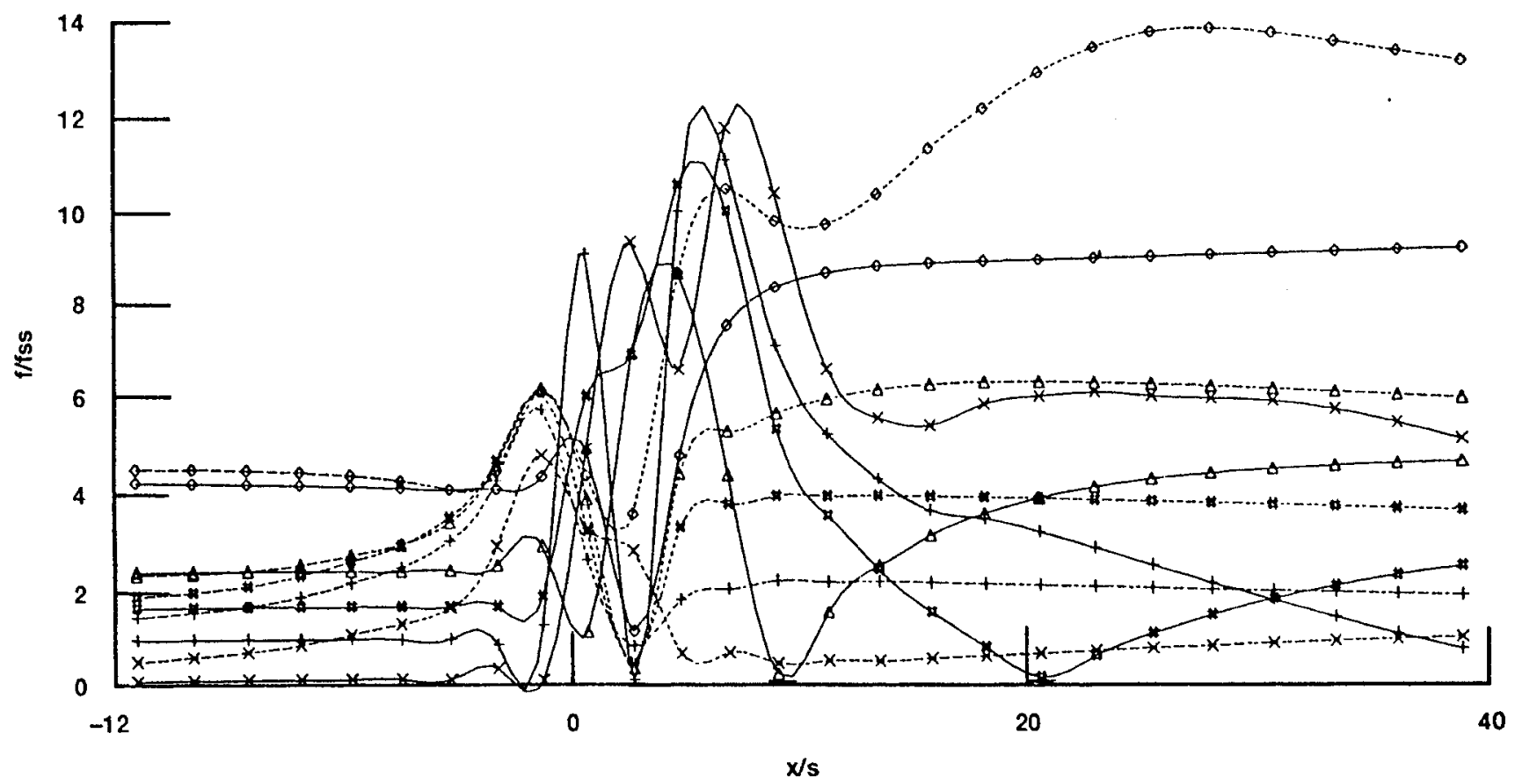

Figure 4.-Normalized friction factor versus dimensionless channel length at different velocity phase angles for asymmetric $1: 2$ change in cross-section. $\operatorname{Re} \max =16500.0, \mathrm{Va}=88.00$. 


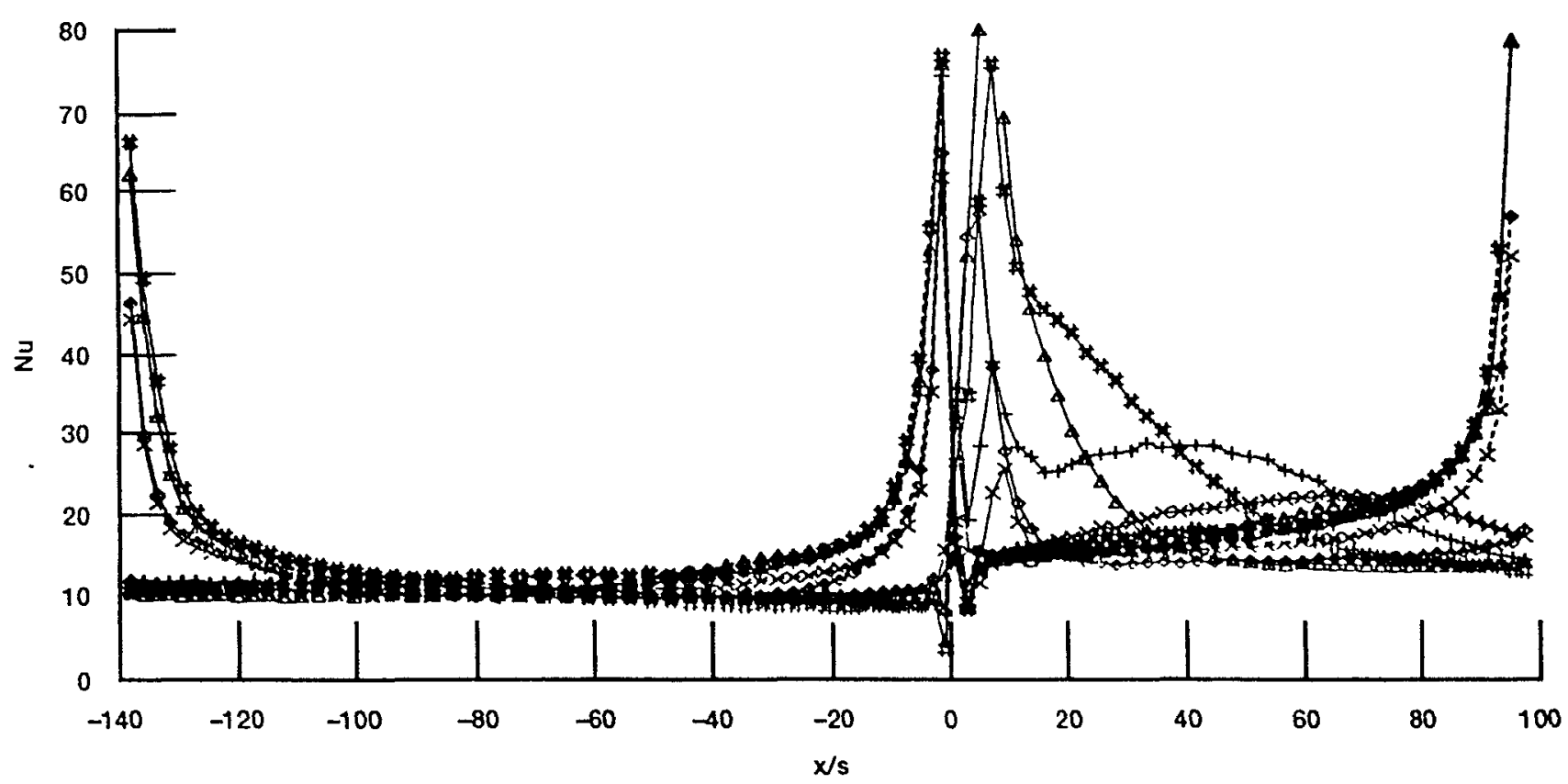

Figure 5.-Nusselt number versus dimenslonless channel length at different velocity phase angles for asymmetric 1:2 change in cross-section. Re $\max =16500.0, \mathrm{Va}=88.00$.

two ends of the channel and at the step, while fully developed cond1tions are observed throughout most of the smaller channel.

\section{CONCLUDING REMARKS}

The following conclusions are drawn from all of the computational results documented by Hashim [12]:

1. For all cases examined, a recurculation zone appeared downstream of the sudden expansion and grew in size as the flow accelerated. $\mathrm{Re}_{\max }$ affects the size of the recirculation zone for a given channel ratio or step height and, also, affects the fluid momentum during flow acceleration and, therefore, the strength of the recirculation zone. For low $\mathrm{Re}_{\max }$ of 187.5 , the recirculation zone decreased in size during deceleration (quasi-steady behavior). For higher $\mathrm{Re}_{\max }$, $>$ or $=1000$, the recirculation zone continued growing dunng deceleration (unsteady behavior). The degree of "unsteadiness" increased with etther $\mathrm{Re}_{\max }$ or $\mathrm{Va}$. For values of $\mathrm{Re}_{\max }$ beyond 5000 , the recirculation zone formed dunng sudden expansion experienced a drift away from the step; this drift increased with $\mathrm{Re}_{\mathrm{max}}$.

2. Va affects the shape of velocity and temperature profiles which in turn affect the values of fnction factor and heat transfer coefficient. For small $\mathrm{Re}_{\max }, \mathrm{Va}$ is the dominant parameter affectıng recirculation zone size. Higher $\mathrm{Va}$ generally restricts recirculation zone growth. For Strouhal number, $\mathrm{St}$, from 0.02 to $0.04, \mathrm{Re}_{\max }$ seems to have the dominant effect on recirculation zone size. However, for St from 0.1 to 0.2 , the effect of $\mathrm{Va}$ overndes the effect of $\operatorname{Re}_{\max }$.

3. The expansion/contraction ratio, for given $\mathrm{Re}_{\max }$ and $\mathrm{Va}$, affects recirculation zone size. Larger ratios result in larger recirculation zones; however, a decrease in velocity magnitude with in the recurculation zone accompanies an increase in size.

4. Three geometries were exammed. It was concluded that an asymmetric geometry is representative of symmetric and blunt body geometries as well, for purposes of the study.
5 Relative fluid displacement, $A_{T}$ accounts for the effect of $L / D_{h}$ on heat transfer for given $S t$ and expansion/contraction ratio. As $A_{r}$ is increased ( $L / D_{h}$ decreased), the heating or cooling surface area decreases, affecting the temperature of the fluid in the channel.

6 Axial pressure drop is affected by $\mathrm{Re}_{\max }, \mathrm{Va}$ and the expansion/contraction ratio. Increasing any of these parameters, independently or together, increases the axial pressure drop.

7. Axial temperature variation is tume dependent and is affected by the axial temperature distribution from the previous half cycle (a "history" effect). Temperature lags behınd velocity. For a heater, the inlet low-temperature fluid produces a temperature distribution which gradually increases from the inlet, by the end of the first half cycle. At flow reversal, the fluid near the new inlet is at a higher temperature than the incoming fluid; in this region a relatively large axial temperature gradient occurs. As the flow accelerates, the fluid temperature gradient is gradually reduced. Finally, towards the end of the second half cycle, a gradually increasing axial temperature distribution is established from inlet to exit.

8. The instantaneous friction factor and heat transfer coefficient deviate substantially from quasi-steady state values for the same flow parameters. These coefficients can be a factor of 10 larger than the quasi-steady-flow values near sudden changes in cross-sectional area.

9. For thermally-expandable flows similar observations, as for incompressible flows, were made. However, the flurd acceleration dunng the sinusoidal velocity vanation is complemented by the acceleration due to density change resulting from fluid heating The values of friction factor and wall heat flux are therefore higher for thermallyexpandable flows than for incompressible flows.

A few final remarks are in order regarding the value of the results for engine design. The results discussed in this paper and documented in full by Hashum [12]: (1) permit visualization of oscillating-flow and temperature fields in the presence of sudden expansion/contractions, (2) show the sensitivity of these fields to the 
hydrodynamic oscillating-flow dimensionless parameters, and (3) convey a qualitative understanding of how a sudden expansion/ contraction affects oscillating-flow friction factors and heat transfer. Thus a study of these results is likely to provide the Stirling designer with insights which enable him to modify hardware in order to produce performance improvements.

When several ongoing tasks are completed, oscillating-flow sudden expansion/contraction effects should be adequately characterized for direct use in Stirling one-dimensional (1-D) design codes. These tasks are: (1) oscillating-flow friction-factor and heat-transfercoefficient (or Nusselt number) correlations must be developed for uniform (no area change) channels; (2) oscillating-flow sudden expansion/contraction computations must be analyzed to characterize how friction factor is affected by cross-sectional area changes, relative to oscillating-flow friction factors for a uniform channel. Resulting "sudden expansion/contraction pressure-loss coefficients" can then be compared with existing steady-flow expansion/contraction pressureloss coefficients, which are currently used in Stirling 1-D design codes; and (3) oscillating-flow sudden expansion/contraction computations must be analyzed to characterize how heat transfer is affected by cross-sectional area changes, relative to oscillating flow with heat transfer in uniform channels.

The comments in the preceding two paragraphs are made with respect to the laminar, incompressible flow computations discussed in this paper. Two-dimensional code improvements are in process that will further impact the derivation of friction-factor and heat transfer correlations for 1-D codes. These are: (1) a transition model is needed to predict laminar/turbulent transition during the course of the cycle. Transition typically occurs from laminar to turbulent and back, twice per engine cycle. A new empirical transition model for oscillating-flow is under development in cooperation with the University of Minnesota; (2) oscillating-flow and oscillating-pressure level calculations will be made with full compressibility accounted for in the basic equations. In Stirling engines, significant changes in density occur with spatial location due to large temperature gradients and with time due to cyclic oscillations in the pressure level (even though the Mach number typically remains low, <0.2). In is anticipated that oscillating-flow sudden cross-sectional area-change effects will need to account for transition and compressibility.

At the same time as these computational efforts are proceeding, experimental flow and heat transfer measurements are underway in the presence of oscillating flow and oscillating pressure level. It is anticipated that interaction between the experimental and computational efforts will result in improved friction-factor and heat transfer correlations for use in Stirling machine design.

\section{REFERENCES}

[1] T.W. Simon, and J.R. Seume, "A Survey of Oscillating Flow in Stirling Engine Heat Exchangers," NASA CR-182108, 1988.

[2] J.R. Seume, "An Experimental Investigation of Transition in Oscillating Pipe Flow," Ph.D. Thesis, University of Minnesota, 1988. [3] M.B. Ibrahim, R.C. Tew, and J.E. Dudenhoefer, "TwoDimensional Numerical Simulation of a Stirling Engine Heat Exchanger," NASA TM-102057, 1989.

[4] U.H. Kurzweg, "Enhanced Heat Conduction in Oscillating Viscous Flows within Parallel-Plate Channels," Journal of Fluid Mechanics, Vol. 156, No. 7, 1985, pp. 291-300.

[5] B.F. Armaly, F. Durst, J.C.F. Pereira, and B. Schonung, "Experimental and Theoretical Investigation of Backward-Facing Step Flow," Journal of Flud Mechanics, Vol. 127, No. 2, 1983, pp. 473-496.

[6] I.T. Chiu, "Prediction of Laminar Flows over Rearward-Facing Step Using the Partially-Parabolized Navier-Stokes Equations," M.S. Thesis, lowa State University, 1984.

[7] O.K. Kwon, R.H. Pletcher, and J.P. Lewis, "Prediction of Sudden Expansion Flows using the Boundary-Layer Equations," Journal of Fluids Engineering, Vol.106, No. 9, 1984, pp. 285-291.

[8] K. Morgan, J. Periaux, and F. Thomasset, "Analysis of Laminar Flow Over a Backward-Facing Step," A GAMM - Workshop, Friedr. Vieweg \& Sohn, Braunschweig. (Notes on Numerical Fluid Mechanics, Vol. 9), 1984.

[9] A. Baron, F.K. Tsou, and W. Aung, "Flow Field and Heat Transfer Associated with Laminar Flow over a Forward-Facing Step," Heat Transfer 1986: Proc. of the 8th Int'l. Conference, San Francisco, Aug. 17-22, 1986, Vol. 3, pp. 1077-1082.

[10] S. Hafez, and M.A. Serag-Eldin, "Computation of the Recirculating Flow Over and Under Bluff-Bodies," Numerical Methods in Laminar and Turbulent Flows: Proc. of the 4th Int ${ }^{* 1}$ Conf., Swanson, July 9-12, 1985, Vol.1, pp. 687-695.

[11] R.W. Mei, and A. Plotkin, "Navier-Stokes Solutions for Laminar Incompressible Flows in Forward-Facing Step Geometries," AIAA Journal, Vol. 24, No. 7, 1986, pp. 1106-1111.

[12] W. Hashim, "Effect of Flow Oscillations on Friction Factor and Heat Transfer Coefficient in a Channel with Sudden Change in Cross Section," M.S. Thesis, Cleveland State University, 1992.

[13] M. Peric, and G. Scheuerer, "CAST - A Finite Volume Method for Predicting Two-Dimensional Flow and Heat Transfer Phenomena," GRS - Technische Notiz SSR-

89-01, 1989.

[14] S.V. Patankar, "Numerical Heat Transfer and Fluid Flow," Hemisphere Publishing Corp., 1980. 
Pubic reporting burden for this coilectron of information is estimated to average 1 hour per response, including the tıme for reviewing instructions, searching existing data sources, gathering and maintaining the data needed, and completing and reviewing the collection of information. Send comments regarding this burden estimate or any other aspect of this collection of information, including suggestions for reducing this burden, to Washington Headquarters Services, Directorate for information Operations and Reports, 1215 Jefferson Davis Highway, Suite 1204, Arlington, VA 22202-4302, and to the Office of Management and Budget, Paperwork Peduction Project (0704-0188), Washington, DC 20503
1. AGENCY USE ONLY (Leave blank) 2. REPORT DATE
1992 3. REPORT TYPE AND DATES COVERED
Technical Memorandum

\section{TITLE AND SUBTITLE}

Heat Transfer in Oscillating Flows With Sudden Change in Cross Section

5. FUNDING NUMBERS

6. AUTHOR(S)

Mounir Ibrahim, Waqar Hashim, Roy C. Tew, and James E. Dudenhoefer

WU-590-13-11

ar Hashim, Roy C. Tew, and James E. Dudenhoefer

7. PERFORMING ORGANIZATION NAME(S) AND ADDRESS(ES)

8. PERFORMING ORGANIZATION REPORT NUMBER

National Aeronautics and Space Administration

Lewis Research Center

Cleveland, Ohio 44135-3191

E-7077

9. SPONSORING/MONITORING AGENCY NAMES(S) AND ADDRESS(ES)

10. SPONSORING/MONITORING AGENCY REPORT NUMBER

National Aeronautics and Space Administration

Washington, D.C. 20546-0001

NASA TM-105692

11. SUPPLEMENTARY NOTES

Prepared for the 27th Intersociety Energy Conversion Enginecring Conference cosponsored by SAE, ACS, AIAA, ASME, IEEE, AIChE, and ANS, San Diego, California, August 3-7, 1992. Mounir Ibrahim and Waqar Hashim, Cleveland State University, Cleveland, Ohio, 44115. Roy C. Tew and James E. Dudenhoefer, NASA Lewis Rescarch Center. Responsible person, Roy C. Tew, (216) 433-8483.

12a. DISTRIBUTION/AVAILABILITY STATEMENT 12b. DISTRIBUTION CODE

Unclassified - Unlimited

Subject Category 20

\section{ABSTRACT (Maximum 200 words)}

Oscillating fluid flow (zero mean) with heat transfer, between two parallel plates with a sudden change in cross section, was examined computationally. The flow was assumed to be laminar and incompressible with inflow velocity uniform over the channel cross section but varying sinusoidally with time. Over 30 different cases were examined; these cases cover wide ranges of $\operatorname{Re}_{\max }(187.5$ to 30000$)$, Va (1 to 350$)$, expansion ratio $(1: 2,1: 4,1: 8$ and $1: 12)$ and $A_{r}(0.68$ to 4$)$. Three different geometric cases were considered (asymmetric expansion/contraction, symmetric expansion/contraction, and symmetric blunt body). The heat transfer cases were based on constant wall temperature at higher (heating) or lower (cooling) value than the inflow fluid temperature. As a result of the oscillating flow, the fluid undergoes sudden expansion in one-half of the cycle and sudden contraction in the other half. In this paper, one heating case is examined in detail, and conclusions are drawn from all the cases (documented in detail elsewhere). Instantaneous friction factors and heat transfer coefficients, for some ranges of $\mathrm{Re}_{\max }$ and $\mathrm{Va}$, deviated substantially from those predicted with steady-state correlations.

14. SUBJECT TERMS

Laminar flow; Oscillating flow; Laminar heat transfer; Channel flow

15. NUMBER OF PAGES

16. PRICE CODE

$\mathrm{AO} 2$

17. SECURITY CLASSIFICATION
OF REPORT
Unclassified

18. SECURITY CLASSIFICATION OF THIS PAGE Unclassified
19. SECURITY CLASSIFICATION OF ABSTRACT Unclassified 
National Aeronautics and

Space Administratton

Lewls Research Center

Cleveland, Ohio 44135

Otileted Bubinese

Penaliny for Privete Uas saod
FOUTTH CLASS MNL

ADDRESS CORAECTION AEQUESTED
|||||

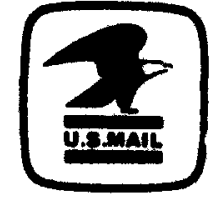

Poslage and Fees Paid Nalional Aeronauliss and

Space Administration NASA 451 